Check for updates

Cite this: RSC Adv., 2017, 7, 37873

Received 8th June 2017

Accepted 21st July 2017

DOI: 10.1039/c7ra06442j

rsc.li/rsc-advances

\title{
Membrane destruction-mediated antibacterial activity of tungsten disulfide $\left(\mathrm{WS}_{2}\right)$
}

\author{
Xu Liu, ${ }^{\text {ab }}$ Guangxin Duan, ${ }^{a}$ Weifeng Li, (D) *a Zhufa Zhou*b and Ruhong Zhou (D) *acd
}

The antibacterial activities of tungsten disulfide $\left(\mathrm{WS}_{2}\right)$ nanosheets against two representative bacterial strains: Gram-negative Escherichia coli (E. coli) and Gram-positive Staphylococcus aureus (S. aureus) were evaluated by colony-forming unit (CFU) studies. The $\mathrm{WS}_{2}$ samples demonstrate a time and concentration dependent antibacterial activity (retardation of bacterial growth) for both bacterial strains. Morphology analyses reveal that $\mathrm{WS}_{2}$ nanosheets adhere to the bacterial surfaces, resulting in robust inhibition of cell proliferation once a bacterium is fully covered with this nanomaterial. More importantly, the intimate contact of $W_{2}$ nanosheets with a bacterium cell membrane can cause serious damage to the membrane integrity, and subsequently the cell death. On the other hand, the reactive oxygen species (ROS) generated by $\mathrm{WS}_{2}$ nanosheets are found to be modest regardless of the $\mathrm{WS}_{2}$ concentration, which is contradictory to the case of its structural analogue, $\mathrm{MoS}_{2}$, where ROS also play a significant role in its antibacterial activity. Taken together, our findings provide a detailed understanding of the antibacterial mechanism of $\mathrm{WS}_{2}$ nanosheets, which might help promote their potential applications in biomedical fields.

\section{Introduction}

Two dimensional (2D) nanomaterials, such as graphene and its derivatives, have attracted considerable attention in recent years with wide applications in electronic and optical devices, ${ }^{1,2}$ drug and gene delivery vehicles, ${ }^{3-7}$ as well as cancer therapeutic platforms..$^{8-12}$ After graphene, the first family member of these 2D nanomaterials, a number of other such nanomaterials have been discovered including phosphorene, silicene and transition metal dichalcogenides (TMDCs). ${ }^{13}$ Among them, the TMDCs, such as $\mathrm{WS}_{2}, \mathrm{MoS}_{2}, \mathrm{WSe}_{2}$, exhibit a considerably high structural stability, with a melting point reaching up to $1185^{\circ} \mathrm{C}$. They have been explored for applications in field-effect transistors, ${ }^{14}$ lithium-ion batteries, ${ }^{15,16}$ integrated circuits, ${ }^{17}$ gas sensors, ${ }^{18}$ hydrogen evolution ${ }^{19}$ and phototransistors. ${ }^{20}$

In particular, the potential antibacterial capabilities of these 2D-nanomaterials have raised considerable interest in recent years. ${ }^{21-23}$ For instance, graphene (and graphene oxide) has been systematically studied ${ }^{24}$ for its antimicrobial activities, ${ }^{25-28}$ along with its underlying molecular mechanisms. ${ }^{29-32}$ It was revealed that graphene and graphene oxide nanosheets can cut into cell

\footnotetext{
Institute of Quantitative Biology and Medicine, SRMP and RAD-X, Collaborative Innovation Center of Radiation Medicine of Jiangsu Higher Education Institutions, Soochow University, Suzhou 215123, China.E-mail: wfli@suda.edu.cn; ruhongz@ us.ibm.com

${ }^{b}$ College of Chemistry, Chemical Engineering and Material Science, Soochow University, Suzhou 215123, China. E-mail: zhouzhufa@suda.edu.cn

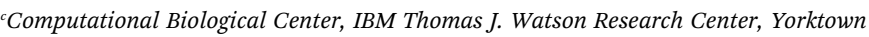
Heights, NY 10598, USA

${ }^{d}$ Department of Chemistry, Columbia University, New York, NY 10027, USA
}

membranes, ${ }^{32}$ extract large amount of phospholipids, ${ }^{32}$ and create holes (pores) on cell membranes, ${ }^{33}$ through large scale molecular dynamics simulations. ${ }^{34-38}$

Compared to graphene and its derivatives, however, there has been much less studies on the antibacterial activities of TMDCs. In 2014, Yang et l. $^{39}$ examined the antibacterial capability of $\mathrm{MoS}_{2}$ and found that $\mathrm{MoS}_{2}$ nanosheets are much more potent than its raw powders. The reasons proposed for this were: (i) $\mathrm{MoS}_{2}$ nanosheets are capable of inducing stronger superoxide anion-independent oxidative stress than raw powders; and (ii) $\mathrm{MoS}_{2}$ nanosheets provide more effective contact areas with the bacteria, which both helped to cause more dramatic membrane stresses in the nanosheet form. Meanwhile, Choi group demonstrated the antibacterial activities of $\mathrm{WSe}_{2}$ nanosheets (in the form of $\mathrm{WSe}_{2}$-ssDNA by exfoliation) mainly through the induction of ROS-independent oxidative stress. ${ }^{22}$ Shinde and co-workers also demonstrated that $\mathrm{WS}_{2}$ can cause retardation in bacterial growth and inhibitory effect on bacterial strains ${ }^{40}$ On the other hand, there are also conflicting reports in literature regarding these TMDCs' antibacterial activities. For instance, Chae and coworkers suggested that $\mathrm{MoS}_{2}$ and $\mathrm{WS}_{2}$ only displayed limited cytotoxicity and genotoxicity, with no significant deleterious effect to cellular viability. ${ }^{41}$

To help resolve some of these apparent discrepancies and also explore deeper the underlying mechanisms, we investigated the antibacterial activity of tungsten disulfide $\left(\mathrm{WS}_{2}\right)$ against two representative bacterial strains: Gram-negative Escherichia coli (E. coli) and Gram-positive Staphylococcus aureus (S. aureus) using the colony-forming units (CFU) method. 
We further examined the ROS generation with an oxidantsensitive DCFH-DA probe and monitored the morphological changes of the bacteria with scanning electron microscope (SEM) and transmission electron microscopy (TEM). We found that the $\mathrm{WS}_{2}$ nanosheets demonstrate a clear cytotoxicity to both $E$. Coli and $S$. aureus bacterial strains. Notably, only limited toxicity was observed in the eukaryotic cells with the control experiments. As revealed from the SEM and TEM results, the $\mathrm{WS}_{2}$ nanosheets can form intimate contacts with the bacteria membranes by adhering onto them. Severe structural damages were observed on these cell membranes, eventually leading to bacterial cell deaths. $\mathrm{WS}_{2}$ is found to be incapable of catalyzing the ROS generation which is in contrast to $\mathrm{MoS}_{2}$. Thus, the antibacterial activity of $\mathrm{WS}_{2}$ nanosheets is mainly attributed to the direct contact of $\mathrm{WS}_{2}$ to the bacteria membrane which causes severe membrane disruption and thus the loss of structural integrity.

\section{Methods and materials}

\subsection{Material preparation and characterization}

The $\mathrm{WS}_{2}$ powders were purchased from Nanjing XFNANO Materials Tech Company limited. The $\mathrm{WS}_{2}$ nanosheets were prepared by the surfactant exfoliation method as reported in previous literature. ${ }^{42}$ The morphology of single-layer $\mathrm{WS}_{2}$ nanosheets was studied by using Veeco AFM in the tapping mode at the scanning rate of $1 \mathrm{~Hz}$ under ambient conditions. The topologies of the samples were further examined by transmission electron microscopy (TEM, Tecnai G220).

\subsection{Bacterial cell preparation and antibacterial activity}

Gram-negative bacteria E. coli (ATCC25922) and Gram-positive bacteria $S$. aureus (ATCC25923) were obtained from the American Type Culture Collection (ATCC, Rockville, Maryland, USA) and used as the model organisms for antibacterial experiments. Bacteria cells were first grown overnight in LB medium (LuriaBertani) at $37{ }^{\circ} \mathrm{C}$ and harvested at the mid-exponential growth phase via centrifugation. Then they were washed three times to remove the residual growth-medium constituents and resuspended in the sterile saline solution $(0.9 \% \mathrm{NaCl}) . \quad \mathrm{A}$ portion of the bacterial suspension was diluted to around $1 \times$ $10^{6} \mathrm{CFU} \mathrm{mL} \mathrm{m}^{-1}$ for antibacterial evaluation. The cells used in all experiments are in the mid-exponential growth phase.

The $\mathrm{WS}_{2}$ nanosheets samples were diluted to a concentration of $0,25,50,100$ and $200 \mu \mathrm{g} \mathrm{mL} \mathrm{m}^{-1}$, respectively, using culture medium with a final concentration of bacteria of $1 \times 10^{6} \mathrm{CFU}$ $\mathrm{mL}^{-1}$. Both E. coli and $S$. aureus were cultured at the condition of $37^{\circ} \mathrm{C}$ for up to $6 \mathrm{~h}$. Antibacterial ability was evaluated by the colony counting method. In brief, the incubation bacterial solutions were initially diluted to $1 \times 10^{4} \mathrm{CFU} \mathrm{mL}^{-1}$. Later, 100 $\mu \mathrm{L}$ of the diluted bacterial cells was spread on the solid LB agar plates. After incubation overnight at $37^{\circ} \mathrm{C}$, colonies on the plates were counted and compared with those on the control plates (without any $\mathrm{WS}_{2}$ nanosheets) to calculate the loss of viability caused by the $\mathrm{WS}_{2}$ nanosheets samples. The reported data were the average value of three separate similar runs.

\subsection{Visualization of bacterial morphology}

Morphological changes of the bacterial morphology were investigated by scanning electron microscopy (SEM) and transmission electron microscopy (TEM). The E. coli and $S$. aureus were incubated with $\mathrm{WS}_{2}$ nanosheets for $2 \mathrm{~h}$ at the concentration of $100 \mu \mathrm{g} \mathrm{mL}{ }^{-1}$, respectively. Subsequently, 10 $\mathrm{mL}$ of bacterial suspensions were harvested by centrifugation at $6000 \mathrm{rpm}$. After quickly fixed with $2.5 \%$ glutaraldehyde and post fixed with $1 \%$ osmium tetroxide, the bacterial cells were dehydrated by using an ascending ethanol series (30\%, 50\%, 70\%, $80 \%, 90 \%, 95 \%$ and $100 \%)$. The samples were then dehydrated overnight, followed by sputter-coated with platinum and mounted for SEM.

\subsection{Reactive oxygen species (ROS) generation measurement}

In order to analyze the generation of ROS induced by $\mathrm{WS}_{2}$ nanosheets, an oxidant-sensitive dye $2^{\prime}, 7^{\prime}$-dichlorofluorescein diacetate (DCFH-DA, Invitrogen detection technologies, USA) was used following the method previously described. ${ }^{\mathbf{4 3 4 4}}$ Briefly, $25 \mu \mathrm{L} 0.1 \mathrm{mM}$ DCFH-DA was treated with $100 \mu \mathrm{L} 0.01 \mathrm{~N} \mathrm{NaOH}$ for $1 \mathrm{~h}$ to generate DCFH, followed by adding $375 \mu \mathrm{L} 0.1 \mathrm{M}$ PBS to terminate this reaction. Next, the $\mathrm{WS}_{2}$ nanosheet samples were added to make the final concentrations: 0, 25, 50, 100 and $200 \mu \mathrm{g} \mathrm{mL}{ }^{-1}$. After $1 \mathrm{~h}$ reaction, the ROS generation was analyzed by a microplate reader at $485 \mathrm{~nm}$ excitation and $530 \mathrm{~nm}$ emission.

\subsection{In vitro cytotoxicity to eukaryotic cells}

In order to further evaluate the $\mathrm{WS}_{2}$ cytotoxicity for eukaryotic cells, adenocarcinomic human alveolar basal epithelial cell line (A549) and human liver cancer cell line (HEP G2) were obtained from the American Type Culture Collection (ATCC, Rockville, Maryland, USA) and respectively cultured with $\mathrm{WS}_{2}$ nanosheets by using the Cell Counting Kit-8 (CCK-8). ${ }^{45}$ Briefly, A549 cells and HEP G2 cells were seeded in a 96-well cell culture plates at the densities of $5 \times 10^{3}$ cell per well, respectively, in DMEM containing $10 \% \mathrm{FBS}$ at $37^{\circ} \mathrm{C}$ in a humid atmosphere of $95 \%$ air and $5 \% \mathrm{CO}_{2}$ for $24 \mathrm{~h}$. After $24 \mathrm{~h}$ incubation, cells reached $\sim 80 \%$ confluence. Subsequently, the cells were incubated with $\mathrm{WS}_{2}$ in serum-free medium, following a similar protocol used in our previous studies, ${ }^{37}$ with $\mathrm{WS}_{2}$ concentrations $12.5,25,50,100$, and $200 \mu \mathrm{g} \mathrm{mL}{ }^{-1}$. The cells cultured in the medium without any nanomaterials were used as the control. After another $24 \mathrm{~h}$ of incubation, the cells were washed with a D-Hanks buffer solution for two times, followed by adding the CCK-8 reagent (10 $\mu \mathrm{L})$. After incubated for additional $2 \mathrm{~h}$ at $37{ }^{\circ} \mathrm{C}$, the spectro photometrical absorbance of each well was measured at $450 \mathrm{~nm}$ wavelength on a microplate reader to calculate the changes of cell viability caused by the $\mathrm{WS}_{2}$ nanosheets. Three replicates were done for each treatment group.

\subsection{Statistical analysis}

All the cell viability tests (Fig. 2c and d and 6) and ROS level results (Fig. 3) were obtained from experiments in triplicates. 
The results are presented as average with standard deviation as error bars.

\section{Results and discussion}

\subsection{Material characterization}

The morphology of the $\mathrm{WS}_{2}$ nanosheets was examined with atomic force microscopy (AFM) and transmission electron microscopy (TEM) first. Fig. 1a depicts the AFM image of the exfoliated $\mathrm{WS}_{2}$ deposited on a mica substrate. The $\mathrm{WS}_{2}$ nanosheets display a flat nanosheet structure coating on the mica surface. The thickness of the $\mathrm{WS}_{2}$ nanosheets is accessed through constructing the height profile diagram along the transverse direction on the mica surface (labeled in Fig. 1a) and the result is shown in Fig. $1 \mathrm{~b}$. The exfoliated $\mathrm{WS}_{2}$ samples are observed to have a typical thickness of $\sim 1 \mathrm{~nm}$, corresponding to around 2-3 layers of $\mathrm{WS}_{2}$ sheets, indicating that the $\mathrm{WS}_{2}$ sheets were well prepared. The TEM images are further taken for the $\mathrm{WS}_{2}$ nanosheets deposited on the glass substrate to give a clearer view of their morphologies (Fig. 1c). The $\mathrm{WS}_{2}$ nanosheets are seen densely packed on the glass surface adopting random orientations.

\subsection{Antibacterial test}

The bactericidal activities of $\mathrm{WS}_{2}$ were evaluated against $E$. coli (Gram-negative) and $S$. aureus (Gram-positive) as two representative bacteria strains. E. coli and S. aureus were incubated with the dispersant of the $\mathrm{WS}_{2}$ nanosheets at concentrations ranging from $25-250 \mu \mathrm{g} \mathrm{mL} \mathrm{m}^{-1}$ at $37^{\circ} \mathrm{C}$ under $250 \mathrm{rpm}$ shaking speed for $2 \mathrm{~h}$ and $6 \mathrm{~h}$. Bacteria incubated at same conditions but without the $\mathrm{WS}_{2}$ nanosheets treatment was used as a control. The death rate of the bacterial cells was determined by the colony counting method.

Fig. 2 summarizes the bacteria viability treated with the $\mathrm{WS}_{2}$ sheets which demonstrate clear bacteria death for both E. coli and $S$. aureus. The viability of bacteria cells dramatically decreased with the increase of the $\mathrm{WS}_{2}$ concentration and the incubation time. In detail, after treated with 25, 50, 100 and 200 $\mu \mathrm{g} \mathrm{mL}^{-1} \mathrm{WS}_{2}$ for $2 \mathrm{~h}$, the viability of $E$. coli was estimated to be $52.3 \%, 12.3 \%, 0 \%$ and $0 \%$, respectively. The $E$. coli survival rate was further reduced at longer incubation time of $6 \mathrm{~h}$. The same trend was also observed for the $S$. aureus. The viability of $S$. aureus was $84.1 \%, 18.0 \%, 4.3 \%$ and $0 \%$ after treated with $\mathrm{WS}_{2}$ at concentrations of $25,50,100$ and $200 \mu \mathrm{g} \mathrm{mL}^{-1}$ for $2 \mathrm{~h}$. These results suggest that the $\mathrm{WS}_{2}$ nanosheets could effectively kill bacteria in a concentration and time dependent manner.

\subsection{Reactive oxygen species (ROS) generation analysis}

As a structural analogue to $\mathrm{WS}_{2}$, another TMDC family member, $\mathrm{MoS}_{2}$, also demonstrates clear antibacterial activity. ${ }^{39}$ The antibacterial activity for $\mathrm{MoS}_{2}$ is found to be induced mainly by two factors: (1) $\mathrm{MoS}_{2}$-bacteria direct contact induced membrane destruction and (2) oxidative stress caused by ROS (generated by $\mathrm{MoS}_{2}$ nanosheets). To probe the possibility of ROS generation by $\mathrm{WS}_{2}$ for its toxicity, we further examined the ROS level to examine whether the bacterial death was caused by oxidative damage using the DCFH-DA probe. DCFH-DA probe without $\mathrm{WS}_{2}$ nanosheets was used as a negative control to validate our tests. The results are shown in Fig. 3. For $\mathrm{WS}_{2}$ concentrations from 25 to $100 \mu \mathrm{g} \mathrm{mL}^{-1}$, the fluorescence intensity only slightly increased, which is distinct to the dramatic decrease of the bacteria viability after $25 \mu \mathrm{g} \mathrm{mL} \mathrm{L}^{-1}$ in Fig. 2 . The absence of strong ROS indicates that the oxygen stress was not the main reason for antibacterial activity of $\mathrm{WS}_{2}$ nanosheets.

\subsection{SEM and TEM analyses of bacteria morphology}

After excluding the ROS generation of $\mathrm{WS}_{2}$ for its antibacterial activity, it is anticipated that the direct contact of $\mathrm{WS}_{2}$ with bacteria membrane and their subsequent interactions might play a key role. Our previous study ${ }^{32}$ on graphene did show that the destruction of the membrane of bacteria (caused by direct contact of graphene and membrane) is a major reason for the bacteria death. To examine whether this is also the case for $\mathrm{WS}_{2}$, the morphological changes of both bacterial cells, E. coli and $S$. aureus, were accessed using SEM images.
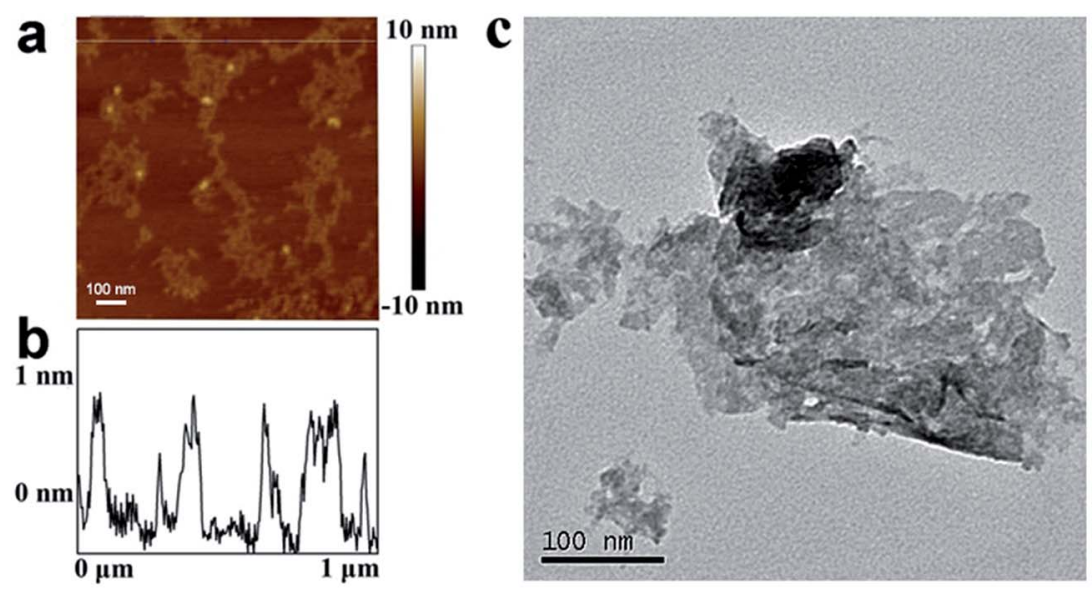

Fig. 1 (a) Atomic force microscopy images of the $W_{2}$ nanosheets deposited on silica substrate, (b) the height profile diagram along the line labelled in (a). (c) Transmission electron microscopy image of one $\mathrm{WS}_{2}$ nanosheet. 

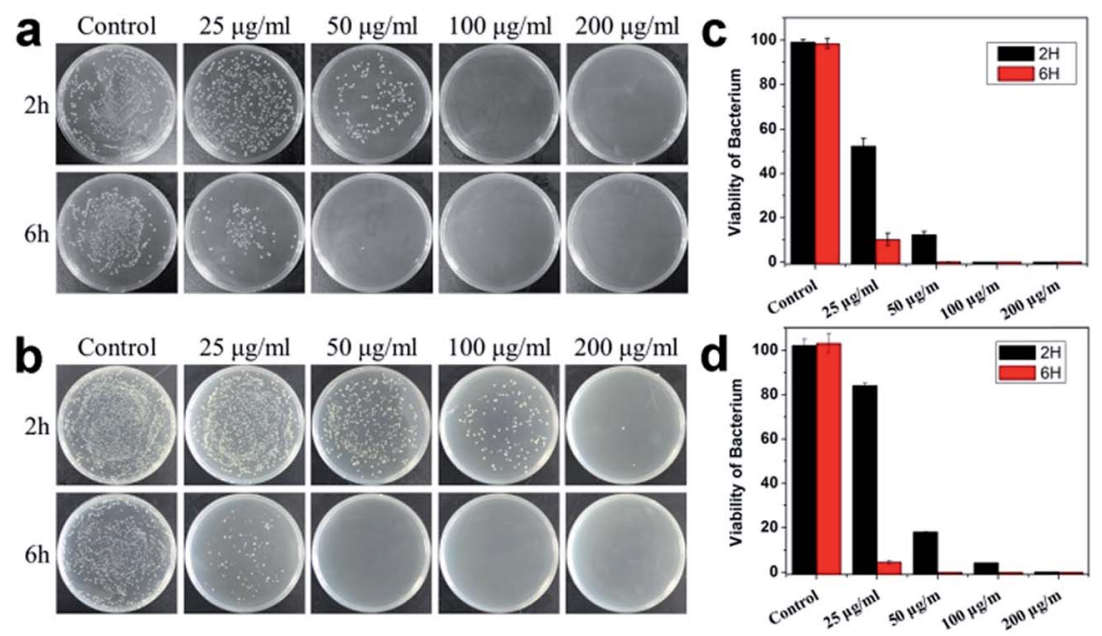

Fig. 2 Antibacterial activity of WS $\mathrm{S}_{2}$ nanosheets. (a and c) Viability of E. coli after treated with $W_{2}$ nanosheets for 2 and 6 h. (b and d) Viability of $S$. aureus after treated with $\mathrm{WS}_{2}$ nanosheets for 2 and $6 \mathrm{~h}$.

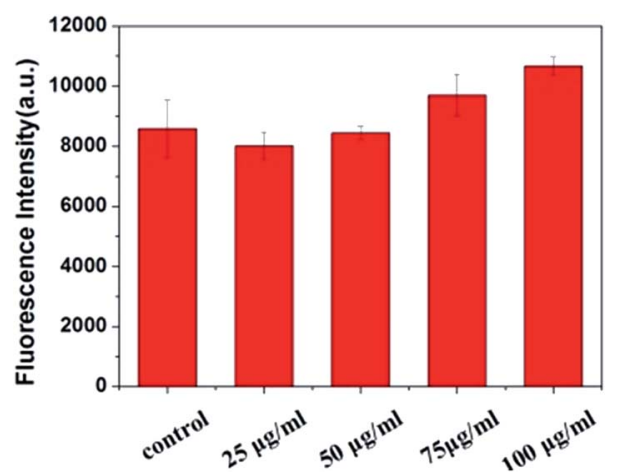

Fig. 3 Concentration-dependent ROS generation induced by $\mathrm{WS}_{2}$ nanosheets was analyzed by DCFH-DA probe. Three replicate samples have been tested for error analyses.

Under the control experiment without the $\mathrm{WS}_{2}$ nanosheets treatment, E. coli exhibited normal rod-like morphology with smooth and intact membranes (Fig. 4a). However, once incubated with $\mathrm{WS}_{2}$ nanosheets for $2 \mathrm{~h}$, severe deformations were observed for $E$. coli cells with their structural damages indicated by arrows in Fig. 4b. Notably, the cell shape became longer and some of them were even drilled, accompanied by formation of large cavities on the surfaces, which is consistent with what we have observed for graphene. ${ }^{33}$ Fig. $4 \mathrm{c}$ displays another example with the $E$. coli cell shape even more seriously distorted and its cell membrane greatly ruptured.

Similar phenomena were observed for S. aureus. The overall morphology of $S$. aureus cells changed from regular sphere shape (the control data, Fig. 4d) to irregular shape (Fig. 4e and f) after incubated with $\mathrm{WS}_{2}$ nanosheets for $2 \mathrm{~h}$, with serious damages on the cell walls indicated by arrows.

Comparing the $\mathrm{WS}_{2}$ treated $E$. coli and $S$. aureus SEM images (Fig. 4b, c, e and f) with control data (Fig. 4a and d), the most significant changes are that the surfaces of dead bacteria are very rich in plate-like particles with sharp edges, indicating that these cell surfaces are mostly likely covered by massive $\mathrm{WS}_{2}$ nanosheets. In addition to the disruption of the cell membranes, these covering $\mathrm{WS}_{2}$ nanosheets might also block various membrane channels and thus cause malfunction of

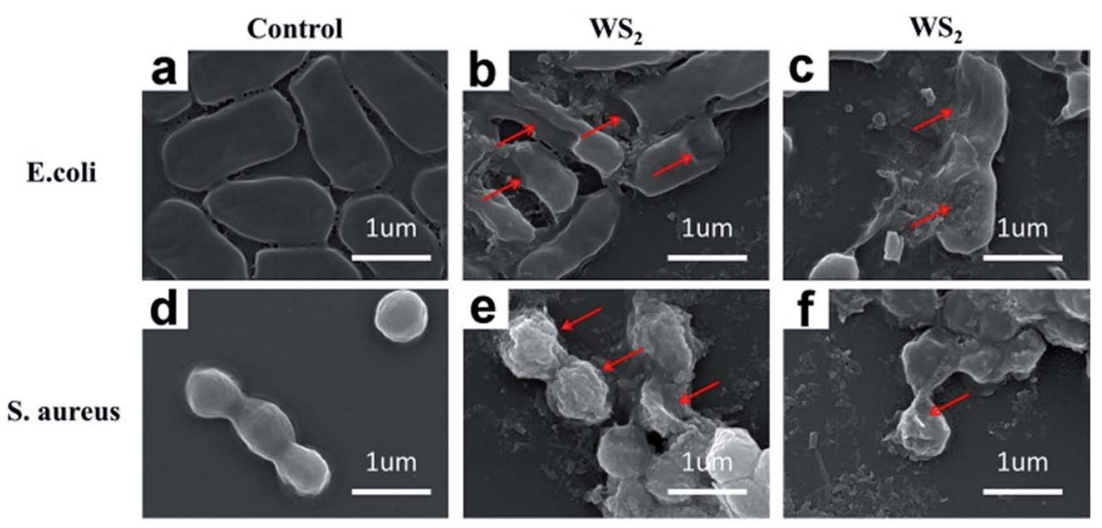

Fig. 4 SEM images of (a) E. coli control (without nanosheets); (b) and (c) E. coli treated with $100 \mu \mathrm{g} \mathrm{mL} \mathrm{m}^{-1}$ of WS ; (d) S. aureus control (without nanosheets); (e) and (f) $S$. aureus treated with $100 \mu \mathrm{gLL}^{-1}$ of $\mathrm{WS}_{2}$. The distorted morphology of the bacteria is indicated by the red arrows. 
selective permeable barriers. This was also suggested for graphene oxide (GO) by Akhavan et al., where GO nanosheets were speculated to prevent the bacteria from exchanging materials with the environment by blocking various membrane channels. $^{46}$

Overall, these SEM images clearly indicate that the irreversible damages are induced on bacterial cells because of their direct contact with $\mathrm{WS}_{2}$ nanosheets. Similar mechanisms were proposed previously by many other groups, ${ }^{47-49}$ with graphene and/or carbon nanotubes, where serious destructions on cell membranes result in membrane stresses and subsequent bacterial cell deaths.

It should be noted that in a previous study, Chae and coworkers suggested that $\mathrm{WS}_{2}$ only displayed limited cytotoxicity and genotoxicity, with no significant deleterious effect to cellular viability. ${ }^{41}$ However, our present study demonstrates a clear antibacterial activity of $\mathrm{WS}_{2}$ to both $E$. coli and $S$. aureus. This apparent discrepancy was first from the fact that Chae and coworkers used human epithelial kidney cells (HEK293f), ${ }^{\mathbf{4 1}}$ i.e. one type of eukaryotic cells, which we also found limited cytotoxicity (more below). Another contribution to this apparent discrepancy is from the morphology of the $\mathrm{WS}_{2}$ samples. The $\mathrm{WS}_{2}$ sheets prepared by Chae was considerably larger and thicker (around 8-10 $\mu \mathrm{m}$ in diameter and 5-8 layers in thickness) than that used in our current study. As characterized in Fig. 1, our $\mathrm{WS}_{2}$ nanosheets have a diameter of $\sim 100 \mathrm{~nm}$ uniformly, and are well separated to be monolayers. These mostly monolayer nanosheets (sharp and free-floating) are expected to interact with the cell membrane in a stronger manner, thus resulting in more membrane stress and destruction. We noticed that such a morphology-dependent cytotoxicity was also previously observed for $\mathrm{MoS}_{2}$ and graphene. Pumera and coworkers reported that the deleterious cytotoxic effects of $\mathrm{MoS}_{2}$ become stronger when the $\mathrm{MoS}_{2}$ nanosheets are better exfoliated. ${ }^{50}$ Another study by Liao et al. also indicated that graphene and graphene oxide are robust in slicing red blood cells when they are in monolayers. ${ }^{51}$ This is believed to be caused by the increase in specific surface areas and sharp edges of $\mathrm{MoS}_{2}$ and graphene nanosheets.

The direct contact of $\mathrm{WS}_{2}$ with bacteria membrane is further confirmed by TEM images. As shown in Fig. 5a, two $\mathrm{WS}_{2}$ particles are found to adhere to $E$. coli surface, one of which has already penetrated into the membrane to a certain extent. Fig. 5b depicts numerous $E$. coli bacteria where $\mathrm{WS}_{2}$ particles are commonly found at the bacteria interfacial and corner regions. Overall, Fig. 5a and b represent an earlier stage of E. coli interaction with $\mathrm{WS}_{2}$. During this stage, the bacteria still demonstrate a rod-like morphology with smooth surface although local deformations can be observed at the $\mathrm{WS}_{2}$ binding site (as indicated in Fig. 5a).

After $2 \mathrm{~h}$ incubation, severe loss of structural integrity was observed for $E$. coli bacteria. Fig. 5c depicts one $E$. coli bacterium
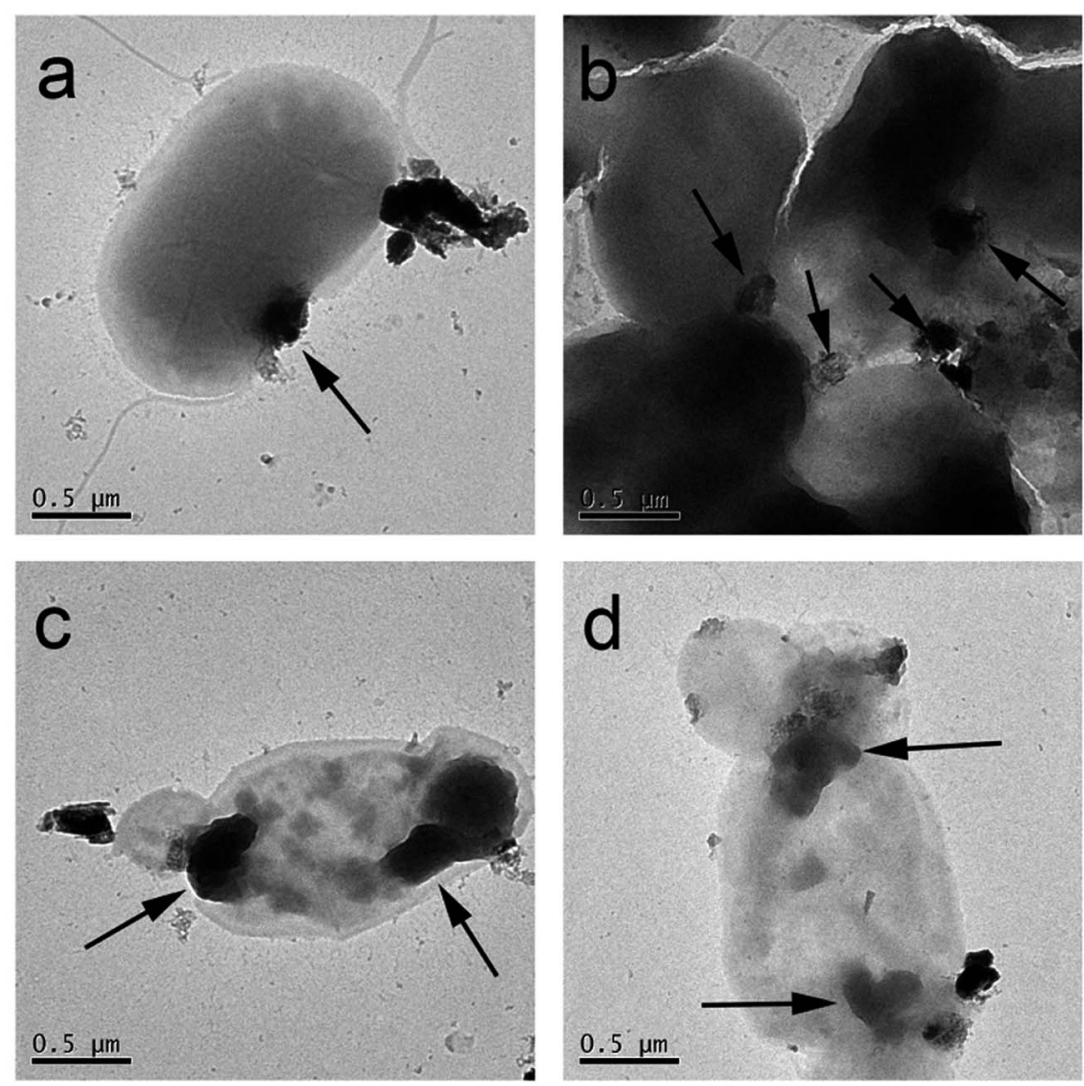

Fig. 5 TEM images of E. coli treated with $100 \mu \mathrm{g} \mathrm{mL} \mathrm{m}^{-1}$ of WS . (a) and (b) were taken immediately after the $\mathrm{WS}_{2}$ treatment, while (c) and (d) were taken after $2 \mathrm{~h}$ incubation. The $\mathrm{WS}_{2}$ particles are indicated by the black arrows. 
interacting with $\mathrm{WS}_{2}$ sheets at two ends of the cell. Clear structural deformations were observed which are mostly uniform at the $\mathrm{WS}_{2}$ binding sites (indicated by arrows in Fig. 5c). Similar phenomenon is seen in Fig. $5 \mathrm{~d}$ where $\mathrm{WS}_{2}$ binds to two regions of cell membrane and causes severe membrane damage. The cell morphologies in Fig. $5 \mathrm{c}$ and $\mathrm{d}$ have been greatly changed compared to those in Fig. 5a and b, indicating that the cell membrane damages are irreversible and fatal. In addition, the cell proliferation is also found to be totally inhibited for these damaged cells (Fig. 5c and d) during the entire incubation process (other TEM images showed similar behavior on the proliferation process of other damaged cells). This inhibition of cell proliferation by nanomaterial coverage was also reported by Akhavan et al. on graphene toxicity towards $E$. coli. ${ }^{46}$ Thus, one can conclude that the damage of cell morphology (and subsequent proliferation) is initiated by the direct contact with $\mathrm{WS}_{2}$ nanosheets.

\subsection{In vitro cytotoxicity to eukaryotic cells}

To further test the potential cytotoxicity of $\mathrm{WS}_{2}$ nanosheets to eukaryotic cells, we used the A549 and HEP G2 cells as two representatives. These two cells are commonly used to evaluate the cytotoxicity of several widely-studied nanomaterials in the recent years, such as graphene oxide, ${ }^{52} \mathrm{MoS}_{2},{ }^{53} \mathrm{Ag}$ nanoparticles $^{54}$ and single walled carbon nanotubes. ${ }^{55}$ The viability of the A549 and HEP G2 cells were examined after exposure to the $\mathrm{WS}_{2}$ nanosheets by the CCK-8 assay. First, A549 and HEP G2 cells were incubated in complete culture medium containing $10 \%$ FBS. After $24 \mathrm{~h}$ incubation, the cells reached $\sim 80 \%$ confluence. Then, these cells were treated with $\mathrm{WS}_{2}$ nanosheets in serum-free medium. The cell viability losses were also observed for both A549 and HEP G2 cells despite that they were less significant than the bacteria. As shown in Fig. 6a and b, the cell viability kept almost a constant at low $\mathrm{WS}_{2}$ concentration (12.5 and $25 \mu \mathrm{g} \mathrm{mL}{ }^{-1}$ ), although a slight decrease was detected for HEP G2. Further increasing of the $\mathrm{WS}_{2}$ concentration would induce severe loss of the cell viability. In addition, the loss of A549 cells viability is systematically higher than HEP G2, which is $30 \%, 43 \%$, and $51 \%$ at the $\mathrm{WS}_{2}$ concentrations of 50,100 and
$200 \mu \mathrm{g} \mathrm{mL}{ }^{-1}$ respectively (Fig. 6a). In comparison, the loss of HEP G2 cells viability was lower, which are $22 \%, 23 \%$ and $26 \%$ at the $\mathrm{WS}_{2}$ concentrations of 50,100 and $200 \mu \mathrm{g} \mathrm{mL} \mathrm{mL}^{-1}$, respectively (Fig. 6b). Generally, $\mathrm{WS}_{2}$ displays a significantly lower cytotoxicity to eukaryotic cells as compared to both Gram-negative and Gram-positive bacteria. This result is consistent with antibacterial studies of other 2D nanomaterials like GO. ${ }^{56}$ The lower cytotoxicity to eukaryotic cells than bacteria seems to be a common feature for the nanomaterials. While a well-documented mechanism is still absent, a possible reason is proposed to be the existence of nuclear membrane in eukaryotic cells. In addition, as suggested from our previous studies, ${ }^{57}$ biomolecules like proteins can rapidly adsorb onto nanomaterial surfaces to form protein corona which can effectively reduce their cytotoxicity. In our current study, $\mathrm{WS}_{2}$ nanosheets were probably partially coated with protein FBS in the cell viability assays, even though the culture media of A549 and HEP G2 cells were replaced with $\mathrm{WS}_{2}$-loaded serum-free media after reaching $\sim 80 \%$ confluence..$^{57,58}$ In other words, our current A549 and HEP G2 cell experiments are more similar to Chae and coworkers' experiment on HEK293f as mentioned above. On the contrary, in the antibacterial experiments, the $\mathrm{WS}_{2}$ nanosheets were kept "naked" during the entire incubation with bacteria.

It is worth noticing that $\mathrm{WS}_{2}$ also exhibits considerably lower toxicity than graphene and graphene derivatives (even at the high $\mathrm{WS}_{2}$ concentration of $\left.200 \mu \mathrm{g} \mathrm{mL}{ }^{-1}\right) .{ }^{59}$ The reason for the more benign toxicity than graphene is caused by the distinct chemical structures of the two materials. For $\mathrm{WS}_{2}$, there is intrinsic electron transfer from $\mathrm{W}$ to $\mathrm{S}$ atoms on the nanosheet, making $\mathrm{WS}_{2}$ somewhat more hydrophilic. While for graphene (graphene oxide also has large un-oxidized $\mathrm{sp}^{2}$ domains on its surface), it is more hydrophobic; and meanwhile, its unique compact structure possesses strong dispersion interactions with other molecules such as phospholipids. Thus, the interactions between graphene and lipids are so strong that it not only causes graphene penetration into cell membranes but also results in destructive extraction of lipids from cell membranes. ${ }^{32}$
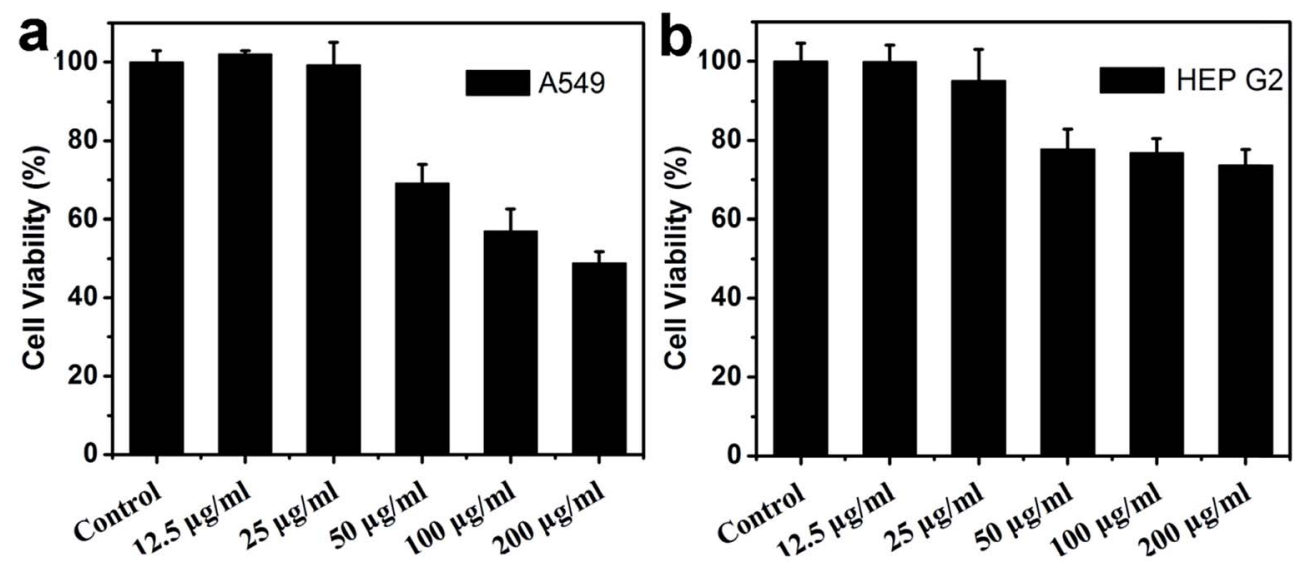

Fig. 6 Cell viability of A549 (a) and HEP G2 (b) as measured using CCK 8 method, following 24 h exposure to varying amounts of WS 2 . 


\section{Conclusion}

The antibacterial activity of the tungsten disulfide $\left(\mathrm{WS}_{2}\right)$ nanosheets was evaluated by the colony counting method. It was found that $\mathrm{WS}_{2}$ nanosheets exhibit a remarkable antibacterial activity towards both $E$. coli (Gram-negative) and $S$. aureus (Gram-positive). The viability of bacteria cells dramatically decreases with the increase of the $\mathrm{WS}_{2}$ concentration and incubation time. As observed by the SEM and TEM images, the $\mathrm{WS}_{2}$ nanosheets could easily cover cells to prevent bacteria from proliferating and induce structural damage. Meanwhile, our results reveal that the ROS generated by $\mathrm{WS}_{2}$ is very modest. Thus, the antibacterial activity of $\mathrm{WS}_{2}$ nanosheets is mainly attributed to the loss of structural integrity of bacterial membrane that is induced by direct contact with the nanomaterial instead of oxidative stress observed in the case of graphene. This study, thus, sheds light on the antibacterial activity of the $\mathrm{WS}_{2}$ nanosheets and promotes further research of the TMDC materials for bio-medical applications.

\section{Author contributions}

R. H. Z., and X. L. conceived and designed the experiments. X. L., and G. D. performed the antibacterial experiments. X. L., G. D., W. F. L., and R. H. Z. analyzed the data. X. L., W. F. L, Z. Z. and R. H. Z. co-wrote the paper. All authors discussed the results and commented on the manuscript.

\section{Conflict of interest}

The authors declare no competing financial interests. Correspondence and requests for materials should be addressed to R. H. Z.

\section{Acknowledgements}

The authors gratefully acknowledge the help from Zhao Lin, Jiaying Xu and Tien Huynh. This work was partially supported by the National Natural Science Foundation of China under Grant No. 11304214, 11374221, 11574224, and 21320102003 and China Postdoctoral Science Foundation under Grant No. 2015M581852 and 2016T90487. RZ acknowledges the support from IBM Blue Gene Science Program (W125859, W1464125, W1464164). A Project Funded by the Priority Academic Program Development of Jiangsu Higher Education Institutions (PAPD), and Jiangsu Provincial Key Laboratory of Radiation Medicine and Protection.

\section{References}

1 F. Xia, H. Wang, D. Xiao, M. Dubey and A. Ramasubramaniam, Nat. Photonics, 2014, 8, 899-907.

2 G. Fiori, F. Bonaccorso, G. Iannaccone, T. Palacios, D. Neumaier, A. Seabaugh, S. K. Banerjee and L. Colombo, Nat. Nanotechnol., 2014, 9, 768-779.

3 S. Goenka, V. Sant and S. Sant, J. Controlled Release, 2014, 173, 75-88.
4 M. Karimi, A. Ghasemi, P. Sahandi Zangabad, R. Rahighi, S. M. Moosavi Basri, H. Mirshekari, M. Amiri, Z. Shafaei Pishabad, A. Aslani, M. Bozorgomid, D. Ghosh, A. Beyzavi, A. Vaseghi, A. R. Aref, L. Haghani, S. Bahrami and M. R. Hamblin, Chem. Soc. Rev., 2016, 45, 1457-1501.

5 J. Liu, L. Cui and D. Losic, Acta Biomater., 2013, 9, 9243-9257.

6 K. Yang, L. Feng and Z. Liu, Expert Opin. Drug Delivery, 2015, 12, 601-612.

7 T. Liu, C. Wang, X. Gu, H. Gong, L. Cheng, X. Shi, L. Feng, B. Sun and Z. Liu, Adv. Mater., 2014, 26, 3433-3440.

8 M. Orecchioni, R. Cabizza, A. Bianco and L. G. Delogu, Theranostics, 2015, 5, 710-723.

9 M. Li, A. Zhao, K. Dong, W. Li, J. Ren and X. Qu, Nano Res., 2015, 8, 3216-3227.

10 Z. Huang, Y. Qi, D. Yu and J. Zhan, RSC Adv., 2016, 6, 3103131036.

11 Z. Lei, W. Zhu, S. Xu, J. Ding, J. Wan and P. Wu, ACS Appl. Mater. Interfaces, 2016, 8, 20900-20908.

12 Q. Liu, C. Sun, Q. He, A. Khalil, T. Xiang, D. Liu, Y. Zhou, J. Wang and L. Song, Nano Res., 2015, 8, 3982-3991.

13 H. Zhang, ACS Nano, 2015, 9, 9451-9469.

14 C. Gong, H. Zhang, W. Wang, L. Colombo, R. M. Wallace and K. Cho, Appl. Phys. Lett., 2013, 103, 053513.

15 Z. Luo, J. Zhou, L. Wang, G. Fang, A. Pan and S. Liang, J. Mater. Chem. A, 2016, 4, 15302-15308.

16 H. Yoo, A. P. Tiwari, J. Lee, D. Kim, J. H. Park and H. Lee, Nanoscale, 2015, 7, 3404-3409.

17 R. Cheng, S. Jiang, Y. Chen, Y. Liu, N. Weiss, H.-C. Cheng, H. Wu, Y. Huang and X. Duan, Nat. Commun., 2014, 5, 5143.

18 D. Sarkar, X. Xie, J. Kang, H. Zhang, W. Liu, J. Navarrete, M. Moskovits and K. Banerjee, Nano Lett., 2015, 15, 28522862.

19 A. Ambrosi, Z. Sofer and M. Pumera, Chem. Commun., 2015, 51, 8450-8453.

20 W. Zhang, M.-H. Chiu, C.-H. Chen, W. Chen, L.-J. Li and A. T. S. Wee, ACS Nano, 2014, 8, 8653-8661.

21 T. I. Kim, B. Kwon, J. Yoon, I.-J. Park, G. S. Bang, Y. Park, Y.-S. Seo and S.-Y. Choi, ACS Appl. Mater. Interfaces, 2017, 9, 7908-7917.

22 G. S. Bang, S. Cho, N. Son, G. W. Shim, B.-K. Cho and S.-Y. Choi, ACS Appl. Mater. Interfaces, 2016, 8, 1943-1950.

23 X. Li, J. Shan, W. Zhang, S. Su, L. Yuwen and L. Wang, Small, 2017, 13, 1602660.

24 F. Perreault, A. F. de Faria, S. Nejati and M. Elimelech, ACS Nano, 2015, 9, 7226-7236.

25 L. Shi, J. Chen, L. Teng, L. Wang, G. Zhu, S. Liu, Z. Luo, X. Shi, Y. Wang and L. Ren, Small, 2016, 12, 4165-4184.

26 S. Szunerits and R. Boukherroub, J. Mater. Chem. B, 2016, 4, 6892-6912.

27 Z. Liu, J. T. Robinson, X. Sun and H. Dai, J. Am. Chem. Soc., 2008, 130, 10876-10877.

28 L. Xiao, J. Sun, L. Liu, R. Hu, H. Lu, C. Cheng, Y. Huang, S. Wang and J. Geng, ACS Appl. Mater. Interfaces, 2017, 9, 5382-5391.

29 J. D. Mangadlao, C. M. Santos, M. J. L. Felipe, A. C. C. de Leon, D. F. Rodrigues and R. C. Advincula, Chem. Commun., 2015, 51, 2886-2889. 
30 S. Gurunathan, J. W. Han, A. A. Dayem, V. Eppakayala and J.-H. Kim, Int. J. Nanomed., 2012, 7, e14.

31 S. Liu, T. H. Zeng, M. Hofmann, E. Burcombe, J. Wei, R. Jiang, J. Kong and Y. Chen, ACS Nano, 2011, 5, 6971-6980.

32 Y. Tu, M. Lv, P. Xiu, T. Huynh, M. Zhang, M. Castelli, Z. Liu, Q. Huang, C. Fan, H. Fang and R. Zhou, Nat. Nanotechnol., 2013, 8, 594-601.

33 G. Duan, Y. Zhang, B. Luan, J. K. Weber, R. W. Zhou, Z. Yang, L. Zhao, J. Xu, J. Luo and R. Zhou, Sci. Rep., 2017, 7, 42767.

34 R. Zhou, B. J. Berne and R. Germain, Proc. Natl. Acad. Sci. U. S. A., 2001, 98, 14931-14936.

35 P. Das, J. Li, A. K. Royyuru and R. Zhou, J. Comput. Chem., 2009, 30, 1654-1663.

36 Z. Xia, P. Clark, T. Huynh, P. Loher, Y. Zhao, H. W. Chen, I. Rigoutsos and R. Zhou, Sci. Rep., 2012, 2, 569.

37 Y. Chong, C. Ge, Z. Yang, J. A. Garate, Z. Gu, J. K. Weber, J. Liu and R. Zhou, ACS Nano, 2015, 9, 5713-5724.

38 B. Luan, T. Huynh, L. Zhao and R. Zhou, ACS Nano, 2015, 9, 663-669.

39 X. Yang, J. Li, T. Liang, C. Ma, Y. Zhang, H. Chen, N. Hanagata, H. Su and M. Xu, Nanoscale, 2014, 6, 1012610133.

40 G. R. Navale, C. S. Rout, K. N. Gohil, M. S. Dharne, D. J. Late and S. S. Shinde, RSC Adv., 2015, 5, 74726-74733.

41 J. H. Appel, D. O. Li, J. D. Podlevsky, A. Debnath, A. A. Green, Q. H. Wang and J. Chae, ACS Biomater. Sci. Eng., 2016, 2, 361367.

42 R. J. Smith, P. J. King, M. Lotya, C. Wirtz, U. Khan, S. De, A. O'Neill, G. S. Duesberg, J. C. Grunlan, G. Moriarty, J. Chen, J. Wang, A. I. Minett, V. Nicolosi and J. N. Coleman, Adv. Mater., 2011, 23, 3944-3948.

43 Y. Chang, S.-T. Yang, J.-H. Liu, E. Dong, Y. Wang, A. Cao, Y. Liu and H. Wang, Toxicol. Lett., 2011, 200, 201-210.
44 J. Tian, J. Chen, C. Ge, X. Liu, J. He, P. Ni and Y. Pan, Bioconjugate Chem., 2016, 27, 1518-1524.

45 X. Liu, X. Zhang, M. Zhu, G. Lin, J. Liu, Z. Zhou, X. Tian and Y. Pan, ACS Appl. Mater. Interfaces, 2017, 9, 279-285.

46 O. Akhavan, E. Ghaderi and A. Esfandiar, J. Phys. Chem. B, 2011, 115, 6279-6288.

47 S. Kang, M. Herzberg, D. F. Rodrigues and M. Elimelech, Langmuir, 2008, 24, 6409-6413.

48 S. Liu, L. Wei, L. Hao, N. Fang, M. W. Chang, R. Xu, Y. Yang and Y. Chen, ACS Nano, 2009, 3, 3891-3902.

49 S. Liu, M. Hu, T. H. Zeng, R. Wu, R. Jiang, J. Wei, L. Wang, J. Kong and Y. Chen, Langmuir, 2012, 28, 12364-12372.

50 E. L. K. Chng, Z. Sofer and M. Pumera, Nanoscale, 2014, 6, 14412-14418.

51 K.-H. Liao, Y.-S. Lin, C. W. Macosko and C. L. Haynes, ACS Appl. Mater. Interfaces, 2011, 3, 2607-2615.

52 E. L. K. Chng, C. K. Chua and M. Pumera, Nanoscale, 2014, 6, 10792-10797.

53 D. K. Ji, Y. Zhang, Y. Zang, J. Li, G. R. Chen, X. P. He and H. Tian, Adv. Mater., 2016, 28, 9356-9363.

54 R. Foldbjerg, D. A. Dang and H. Autrup, Arch. Toxicol., 2011, 85, 743-750.

55 A. Casey, E. Herzog, F. Lyng, H. Byrne, G. Chambers and M. Davoren, Toxicol. Lett., 2008, 179, 78-84.

56 W. Hu, C. Peng, W. Luo, M. Lv, X. Li, D. Li, Q. Huang and C. Fan, ACS Nano, 2010, 4, 4317-4323.

57 G. Duan, S.-G. Kang, X. Tian, J. A. Garate, L. Zhao, C. Ge and R. Zhou, Nanoscale, 2015, 7, 15214-15224.

58 C. Ge, J. Tian, Y. Zhao, C. Chen, R. Zhou and Z. Chai, Arch. Toxicol., 2015, 89, 519-539.

59 W. Z. Teo, E. L. K. Chng, Z. Sofer and M. Pumera, Chem.-Eur. J., 2014, 20, 9627-9632. 